Case Report

\title{
Glue That Pain: A Case Report and Review of Literature
}

\author{
Umar Farooq, Asad Abbas, Asfand Baig Mirza, Faiza Nazir, Hiten Mehta, Amjad Shad \\ Department of Neurosciences, University Hospital Coventry and Warwickshire, United Kingdom (UK)
}

\begin{abstract}
Tarlov cysts are cyst like lesions of the spinal nerve roots. With a reported incidence ranging from 1 to $5 \%$, these lesions are fairly rare, benign and often asymptomatic. When they cause neural compression they may become symptomatic with sensory, motor, bowel/bladder and sexual dysfunction. The treatment of Tarlov cysts with symptoms is controversial, ranging from conservative management and local steroid injections to a bewildering assortment of surgical options including CSF diversion procedures and advance microsurgical approaches with various ways of cyst manipulation. All these surgical modalities carry a high risk of serious complications, recurrence with the need of a redo operation and a very variable rate of symptomatic relief ranging from $38-100 \%$ in different series. Developing from the CT guided needle aspiration of the cyst which suffered disappointment in the form of re accumulation and heralded by earlier reports of aseptic meningitis, CT guided aspiration and subsequent filling of the cyst with fibrin glue has now emerged as Initial treatment for Tarlov cyst which is safe and effective.
\end{abstract}

Keywords: Tarlov Cyst, Sacral Lesion, Fibrin Glue, Percutaneous.

Corresponding Author: Asad Abbas

Department of Neurosurgery,

Nottingham University Hospital,

Queens Medical Center,

Nottingham, UK

Email: asad.abbas@live.com

Date of Submission: 20-11-2020

Date of Revision: 05-12-2020

Date of Online Publishing: 25-12-2020

Date of Print: 30-12-2020

\section{DOI: $10.36552 /$ pjns.v24i4.442}

\section{INTRODUCTION}

Tarlov cysts are perineural CSF filled cystic lesions arising in dorsal nerve root ganglion between the endoneurium and perineurium of the nerve root sheath. They are usually asymptomatic, often multiple and mostly located in the sacral region. However, depending upon the size, location and relationship to the nerve root, these lesions may become symptomatic in around 20 to $30 \%$ of the patients, causing compression of the nerve root or sacral plexus, resulting in lower back pain with or without sciatica, and autonomic dysfunction. The decision to treat Tarlov cyst and what modality of treatment to be employed is a difficult one and no consensus exists.

The first step is to identify if the symptoms are purely due to the presence of the cyst or if an overlap of multiple factors exists. The next step is the choice of treatment and a wide variety of 
options ranging from conservative management to advance microsurgical techniques exist.

Surgical options carry higher risk of serious complications (e.g. meningitis, nerve root damage, cauda equina syndrome and CSF leakage), recurrence with need of a redo operation and may not be successful in relieving the symptoms all the time.

Fibrin glue injection under CT guidance is a simple alternate treatment which is safe as well as effective.

\section{CASE REPORT}

$82 \mathrm{~F}$ with Osteoporosis, degenerative lumbar disc disease, bilateral greater trochanteric bursitis, right sided sacroiliac joint pain with radiation down the leg, multiple level facet joint arthrosis and low back pain referring into groin initially thought to be arising from the facet joints. Underwent right Sacroiliac joint and L4/5 L5/S1 blocks with some remission followed by a resurgence of symptoms on the $L t$ side with similar blocks offered on the Lt side. The remission lasting only 8 weeks. She received several cycles of local blocks, but her symptoms continued to get worse with declining urinary function as well. MRI and high resolution CT showed evidence of a sizable Tarlov cyst at S2/3 level with expansion of bilateral sacral foramina bilaterally (Figure 1).

She was offered a CT guided aspiration and after confirmation of symptomatic relief a definitive CT guided aspiration with simultaneous fibrin glue instillation was performed with complete resolution of her symptoms including urinary function improvement (Figures $2-4$ ). She has been symptom free for 24 months of followup.

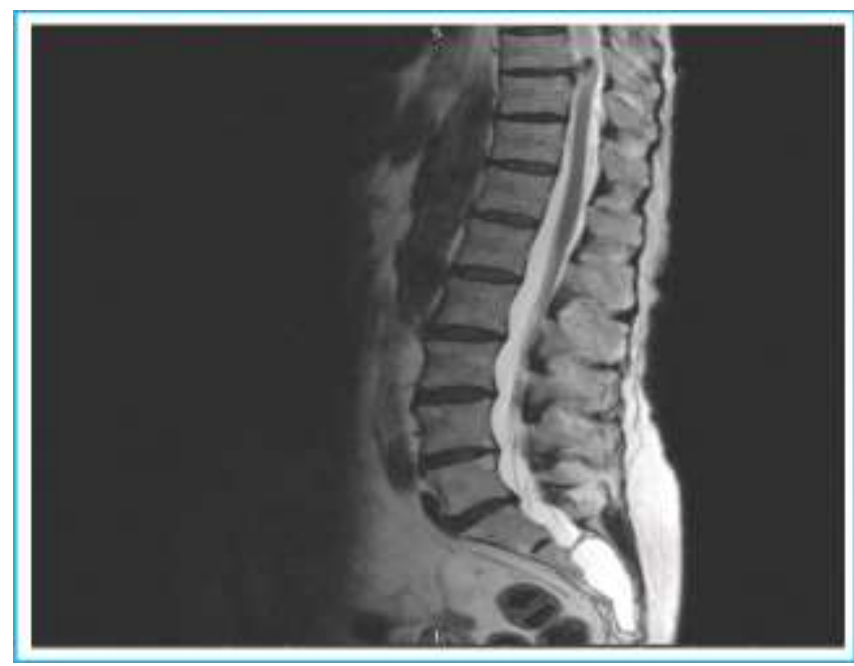

Figure 1: MRI T2 weighted images showing the presence of Tarlov cyst at S2/3.

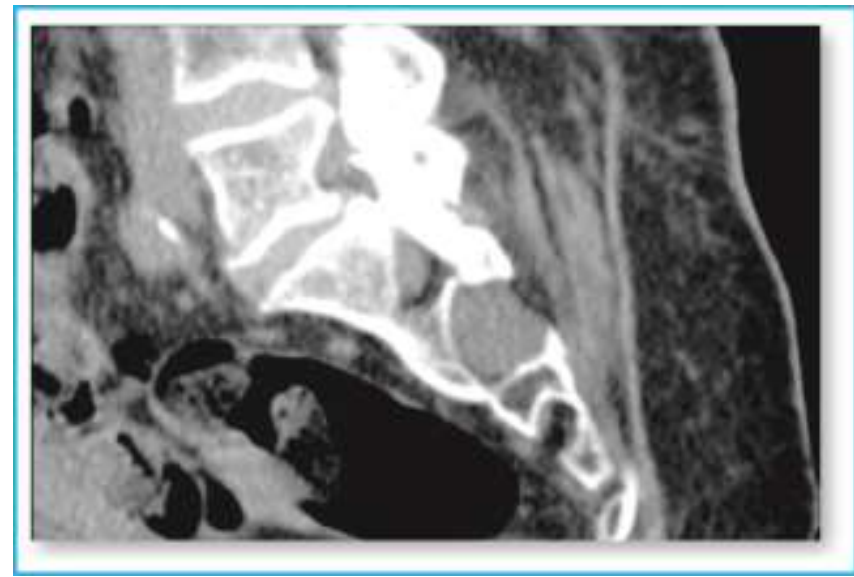

Figure 2: Tarlov Cyst at S2/3 level; Pre-op check.

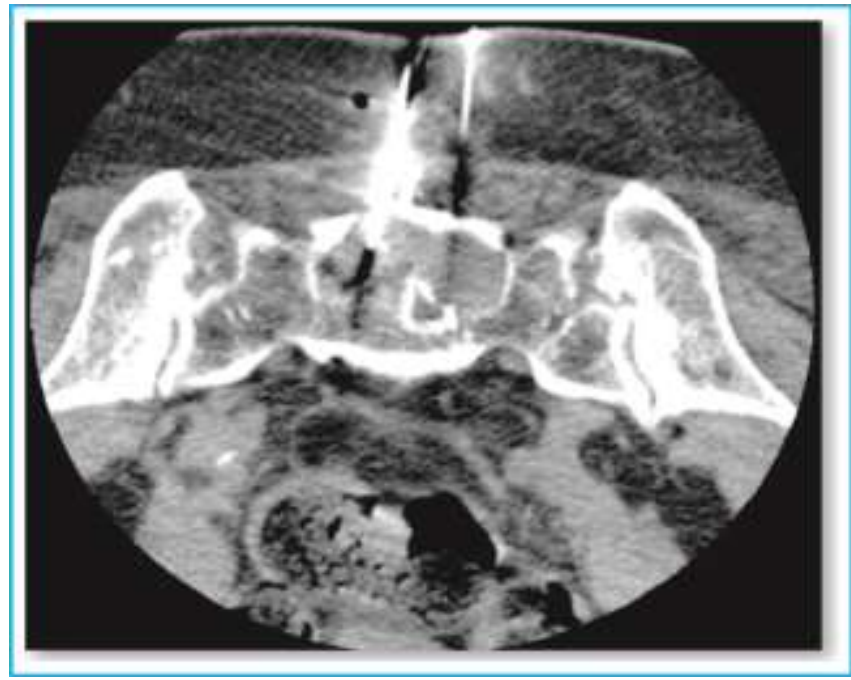

Figure 3: CT guided Needle aspiration of Tarlov Cyst. Pak. J. of Neurol. Surg. -2020 - 24 (4): 387-392. 388 


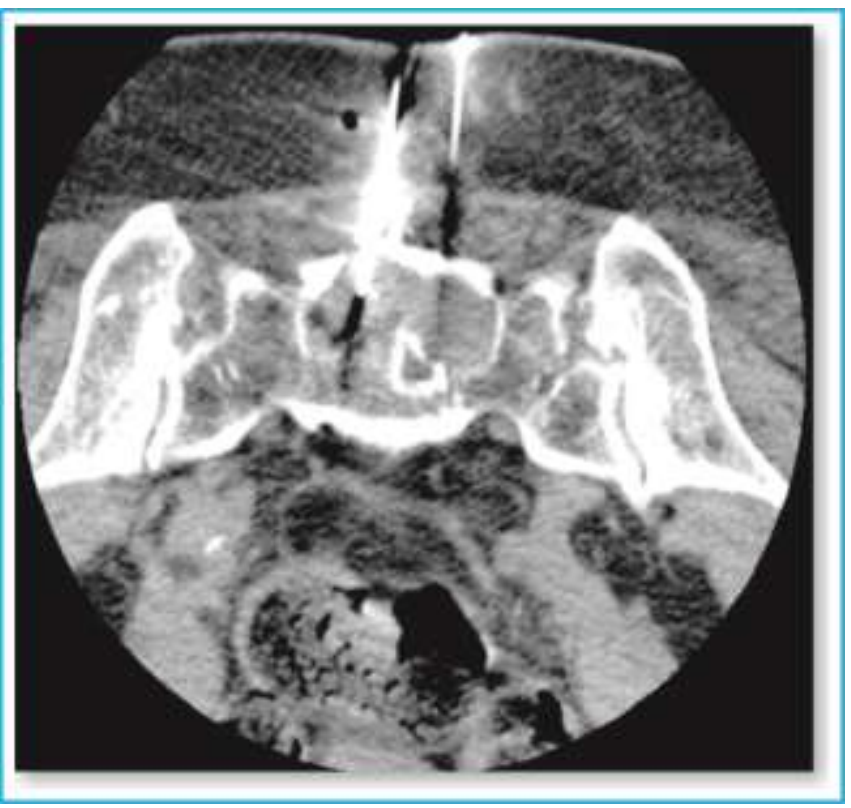

Figure 4: Simultaneous CT guided fibrin glue instillation of the cyst.

\section{DISCUSSION}

\section{Incidence}

With the wide availability of MRI, CT scan and CT Myelogram, the incidental finding of Tarlov cysts has become very common and with an incidence rate of 1 to $5 \%$, they are second only to vertebral haemangiomas as the most common incidental lumbosacral lesions. - Padma? Some recent series have even descried an incidence rate of as high as 9\%. ${ }^{4}$ Park et al. Found that between the sexes there is no considerable distinction in prevalence. On the other hand, there seems to be a difference in incidence regarding age, as Tarlov cysts seem to be more frequent in younger people, $4.0 \%$ (under 50 years old) as opposed to $1.3 \%$ (over 50 years old). ${ }^{11}$

\section{Definition, Classification and Histology}

By definition Tarlov cysts are CSF-filled cystic lesions located in dorsal nerve root ganglion in the extradural space the nerve root sheath. ${ }^{4,10,11}$

Originally described by Tarlov in 1938 as "perineural cysts", 2,3 established by his observations on cadaveric dissection, he noted these cysts to be often multiple in number, sacral or coccygeal in location and extradural in nature. He identified three essential characteristics when examining the cysts histologically. ${ }^{18-20}$ Firstly, on myelographic examination, these perineural cysts may demonstrate prolonged or insufficient filling due to the latent communication with the spinal subarachnoid space. Secondly, unlike meningeal diverticula, Tarlov cysts typically occur in the sacral region, on or distal to the junction between dorsal root ganglion and posterior nerve root. Lastly, a segment of the wall of the perineural cysts is comprised of ganglion cells and nerve fibers. As a result of these three observations he distinguished Tarlov cysts from meningeal diverticula. ${ }^{8,9}$

There are two classification systems for Intraspinal cysts, firstly Goyal, et al. have classified the cysts in to five categories: 1) Perineurial (Tarlov) cyst; 2) nerve root sleeve dilation, 3) arachnoid (intradural) cyst; 4) arachnoid (extradural) cyst; and 5) traumatic cyst of anerve root. $^{3}$

Nabors et al. have recently classified them into three types. Types 1 and 2 are extradural without or with spinal nerve root fibres, respectively. Whereas, type 3 meningeal cysts are intradural. ${ }^{8}$ Type 2 cysts in this classification are called Tarlov cysts.

\section{Etiology and Pathophysiology}

The cause of Tarlov cyst remains perplexing. Tarlov (1952) hypothesized that the cysts occurred due to an inflammatory process involving the nerve root sheath, resulting in the formation of a cyst. Nishiura et al described how $40 \%$ of their patients who had Tarlov cysts had a history of antecedent trauma. ${ }^{21,22}$ However, the majority of surgeons recognize that the cysts are a congenital defect. ${ }^{1}$

The ball valve theory relies on the fact that a channel exists between the cyst and subarachnoid 
space. The cysts, which have a ball valve mechanism in play, fill and expand under the effect of gravity and pulsatile forces and as a result cause compression on the nervous tissue causing symptoms. However, the so-called "unvalved cysts" have anopen channel between the cyst and the subarachnoid space and CSF is free to enter and leave the cyst, remain asymptomatic.

\section{Radiology}

$M R I$ is the investigation of choice for cysts and on MR imaging, the cysts are hypointense on T1 and hyperintense on T2 weighted images, appearing as fluid-filled lesions. ${ }^{13}$ CT scan is very helpful in aiding with aspiration and injection forfibrin glue. ${ }^{14}$ CT Myelogram can be used to delineate the connection between the cyst and the subarachnoid space. ${ }^{14}$ However, the role of plain radiograph is very limited.

\section{Clinical Presentation}

Tarlov Cysts are mostly asymptomatic and are usually discovered as an incidental finding on a lumbosacral MR done for other reasons. However, 20 to $30 \%$ of the time these lesions may cause compression to the nerve root or sacral plexus, resulting in back, sacrococcygeal, perianal and lower limb radicular pain, neurogenic claudication, leg weakness and autonomic dysfunction (bowel/bladder or sexual). ${ }^{1,2,5}$

Infrequently, actions increasing subarachnoid pressure, such as coughing, defecation and standing, can aggravate the radicular symptoms, by forcing the CSF into the perineural cyst space by means of a ball valve-like interaction. ${ }^{6,15}$

\section{Indications and Treatment Options}

The decision to treat Tarlov cyst and what modality of treatment to be employed is a difficult one and no consensus exists. The first step is to identify if the symptoms are purely due to the presence of the cyst alone or if another cause such as a disc prolapsed etc., exists. If an overlap of multiple factors exists, how much of it is caused by the cyst itself and requires treatment or could the symptoms be resolved by taking care of the primary pathology alone. The next step is the choice of treatment and a wide variety of options ranging from conservative management to advance microsurgical techniques exists.

\section{Surgical Intervention and Pitfalls}

Surgical options can be divided into CSF diversion procedures like lumbo-peritoneal and cystosubarachnoid shunts, and surgical decompressive techniques ranging from simple posterior sacral decompression to advance microsurgical approaches with various ways of cyst manipulation in the form of resection, imbrication, fenestration, removal of the cyst with sacrifice of the parent root, with filling of cyst cavity with absorbable gelatin sponge, fibrin glue and muscle or fat and covering the dural defect.

Surgical procedures carry a high risk of serious complications, CSF leak being the commonest, meningitis, nerve root damage, cauda equina syndrome due to migration of the muscle patch have also been reported.

\section{CT Guided Aspiration and Fibrin Glue Injection}

Patel et al. first described the procedure in 1997 in their series of 4 patients where symptomatic Tarlov cysts were first aspirated with a needle under CT guidance. However recurrence of symptoms occurred within $17-28$ weeks, as a result the procedure was repeated with fibrin glue being injected post aspiration of the cyst and this resulted in patients remaining symptom free upto 1 year and 11 months in his initial report. The technique was initially abandoned due to fear of aseptic meningitis which 3 out of the 4 patients were thought to exhibit as an early post op 
complication. $^{12}$ Later on there was renewed interest in the technique and Murphy et al published the largest series in 2007 with 122 symptomatic patients with Tarlov cyst (84\% Women, Mean age 54 years. $^{7}$ A high proportion of the patients presented with symptoms ranging from lumbar and buttock pain, and radicular symptoms involving the sacral dermatomes. (perianal region and lower limb). ${ }^{7}$ Only nine patients has symptoms of bowel and urinary dysfunction who underwent cyst aspiration and fibrin glue injection. $65 \%$ of patients showed improvement as a result of the procedure and $19 \%$ demonstrated marked or complete resolution of symptoms. ${ }^{7}$ The only complications were transient sciatica ( 6 patients), transient rectal fullness ( 1 patient) and urticaria from an unknown origin (1 patient). None of the patients experienced aseptic meningitis post-op.

In their vast experience they found that the most crucial contraindication to fibrin glue injection is wide cyst neck. As there is a danger of extravasation of glue into thecal sac, which can free flow into CSF resulting in aseptic meningitis. ${ }^{7}$ Patients who are discovered to have a high refilling rate of CSF into the cyst are better off with surgical intervention as well.

More recently in 2011 S Yang et al reported their series of 38 patients with fibrin glue injection of symptomatic Tarlov cysts under CT guidance following aspiration with an excellent/good recovery in $86.8 \%$ patients with no disabling complications. $^{14}$

\section{CONCLUSION}

CT guided percutaneous aspiration and fibrin glue injection is a simple therapy which is safe and effective for symptomatic Tarlov cysts.

\section{REFERENCES}

1. Hoshino $Y$, Edakuni $H$, Shimada $H$, et al. Sacral arachnoid cyst associated with Marfan syndrome.
Intern Med. 2005; 44: 271-73.

2. Acosta Jr FL, Quinones-Hinojosa $A$, Schmidt $M H$, Weinstein PR. Diagnosis and management of sacral Tarlov cysts: case report and review of the literature. Neurosurgical focus, 2003; 15 (2): 1-7.

3. Goyal RN, Russell NA, Benoit BG, et al: Intraspinal cysts: a classification and literature review. Spine, 1987; 12: 209-213.

4. Guo D, Shu K, Chen R, Ke C, Zhu Y, Lei T. Microsurgical treatment of symptomatic sacral perineurial cysts. Neurosurgery, 2007; 60: 1059-65.

5. Langdown AJ, Grundy JR, Birch NC. The clinical relevance of Tarlov cysts. J Spinal Disord Tech. 2005; 18: $29-33$.

6. Mummaneni PV, Pitts LH, McCormack BM, et al: Microsurgical treatment of symptomatic sacral Tarlov cysts. Neurosurgery, 2000; 47: 74-79.

7. Murphy K, Nussbaum D, Schnupp S, Long D. Tarlov Cysts: An Overlooked Clinical Problem. Seminars in Musculoskeletal Radiology, 2011; 15 (02): 163-7.

8. Nabors MW, Pait TG, Byrd EB, Karim NO, Davis DO, Kobrine Al, et al. Updated assessment and current classification of spinal meningeal cysts. J Neurosurg. 1988; 68: 366-377.

9. Nishiura I, Koyama T, Handa J: Intrasacral perineurial cyst. Surg Neurol. 1985; 23: 265-269,

10. Padma S, Palaniswamy SS. Multilocular disseminated Tarlov cysts: Importance of imaging and management options. Indian J Nucl Med. 2012; 27: 111-4.

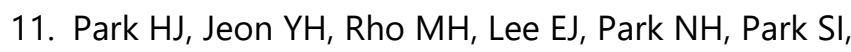
et al. Incidental findings of the lumbar spine at MRI during herniated intervertebral disk disease evaluation. AJR Am J Roentgenol. 2011; 196: 11515.

12. Patel MR, Louie W, Rachlin J. Percutaneous fibrin glue therapy of meningeal cysts of the sacral spine. AJR Am J Roentgenol. 1997; 168: 367- 370.

13. Paulsen RD, Call GA, Murtagh FR: Prevalence and percutaneous drainage of cysts of the sacral nerve root sheath (Tarlov cysts). AJNR. 1994; 15: 293-297.

14. Shao Z, Wang B, Wu Y, Zhang Z, Wu Q, Yang S. CTGuided Percutaneous Injection of Fibrin Glue for the Therapy of Symptomatic Arachnoid Cysts. American Journal of Neuroradiology, 2011; 32 (8): 1469-73.

15. Strully KJ, Heiser S: Lumbar and sacral cysts of meningeal origin. Radiology, 1954; 62: 544-549. 
16. Strully KJ. Meningeal diverticula of sacral nerve roots (perineural cysts). JAMA. 1956; 161: 1147-52.

17. Tanaka $M$, Nakaharab $S$, Ito $Y$, et al. Surgical results of sacral perineural (Tarlov) cysts. Acta Med Okayama. 2006; 60: 65-70.

18. Tarlov IM: Cyst of the sacral nerve roots: clinical significance and pathogenesis. Arch Neurol Psychiatry, 1952; 68: 94-108.

19. Tarlov IM: Perineural cysts of the spinal nerve roots. Arch Neurol Psychiatry, 1938; 40: 1067-1074.
20. Tarlov IM: Sacral Nerve-Root Cysts: Another Cause of the Sciatic or Cauda Equina Syndrome. Springfield, IL: Charles C. Thomas, 1953: pp 56-116.

21. Tarlov IM. Sacral Nerve Root Cysts: Another Cause of the Sciatica or Cauda Equina Syndrome. Springfield, Illinois: Charles C. Thomas, 1953: 56116.

22. Williams B. Sciatica caused by sacral-nerve-root cysts. Lancet. 1971; 1: 137.

\section{Additional Information}

Disclosures: Authors report no conflict of interest.

Human Subjects: Consent was obtained by all patient(s)/participant(s) in this study.

Ethical Review Board Approval: The study was conformed to the ethical review board requirements.

Previous Presentation: The Case report was presented at SBNS Autumn meeting in Coventry, 2014.

\section{Conflicts of Interest:}

In compliance with the ICMJE uniform disclosure form, all authors declare the following:

Financial Relationships: All authors have declared that they have no financial relationships at present or within the previous three years with any organizations that might have an interest in the submitted work.

Other Relationships: All authors have declared that there are no other relationships or activities that could appear to have influenced the submitted work.

\section{AUTHORS CONTRIBUTIONS}

\begin{tabular}{|l|l|l|}
\hline Sr.\# & Author's Full Name & Intellectual Contribution to Paper in Terms of: \\
\hline 1. & Umar Farooq & $\begin{array}{l}\text { 1. Study design, methodology, and Manuscript } \\
\text { writing. }\end{array}$ \\
\hline 2. & Asad Abbas & 2. Paper writing, referencing and data calculations \\
\hline 3. & Asfand Baig Mirza & 3. Data collection and calculations. \\
\hline 4. & Faiza Nazir & 4. Analysis of data and interpretation of results. \\
\hline 5. & Hiten Mehta & 5. Literature review \\
\hline 6. & Amjad Shad & 6. Literature review and final proof read. \\
\hline
\end{tabular}

